\title{
Investigation of vapor film motion regularities at boiling liquids
}

\author{
A. Agaltsov ${ }^{1}$ and Yu. Zeigarnik ${ }^{1}$ \\ ${ }^{1}$ JIHT RAS, 125412 Moscow, Russia
}

\begin{abstract}
The experimental investigation of the saturated Freon-113 and distilled water film boiling on spheres with different diameters at atmospheric pressure under conditions of free convection is executed. With high-speed video average thickness and cumulative distribution function of vapor film as a function of the angle was measured. It was found that with increasing the angle the average thickness of vapor film can change by different laws depending on diameter of the sphere and the temperature difference. It was found also that the increase in the average vapor film thickness with increasing angle is more connected with the increase of large components of cumulative distribution function. It also noted the presence of quasi-periodic pulsations of the vapor film thickness in the lower part, which eventually largely determine the behavior of the interface at large angles.
\end{abstract}

\section{Introduction}

Film boiling process is realized at sufficiently large heattransfer surface superheats relatively saturated temperature of boiling liquid, which occurs, for example, during the quenching of steel products and when cooling down of cryogenic systems. And thus a detailed understanding of film boiling can help develop new techniques and design new modern equipment in these areas. Another important reason for study the physics of film boiling is a phenomenon of the vapor explosion, which may lead to colossal damage in emergency situations in nuclear power plants and steel plants.

In general, in terms of using the two-phase heat transfer as the most effective way to remove heat from the surface, a more preferred modes are nucleate and transition boiling, in which the heat transfer coefficient at times or on the order more than in the case of film boiling. However, in [1] reported a significant increase in heat transfer at film boiling of subcooled water. The causes and mechanisms of this phenomenon currently is not fully understood. For this reason, it is also important a more thorough study of hydrodynamics and heat transfer at film boiling.

It should be noted that in recent years to analyze the process of film boiling numerical simulation methods, for example, based on Volume of fluid (VOF) [2,3], had been developed. Undoubtedly, the comparison of the numerical solution of the time and temperature dependence of the vapor film thickness with experimental data helps adjust the methodology and more adequately apply the assumptions made in the construction of the model equations.
One of the most interesting and important to understand the physics of film boiling problem is to study the behavior of the liquid-vapor interface. Unfortunately, it should be noted that, despite the significant influence of the interface unevenness on the local and integral heat transfer, as well as the instant and time-averaged temperature distribution in the heater, this problem isn't studied enough due to the lack of attention. Now there are very limited theoretical and experimental studies covering this aspect [4-7].

In this paper we present experimental data on the movement regularities of the liquid-vapor interface at film boiling of saturated liquids under conditions of free convection on spherical heaters various diameters and at various temperature differences.

\section{Experimental facility and method}

Investigations were made on the experimental installation which scheme is shown on figure 1 . Tank with test liquid (1) was a horizontal cylindrical vessel with an inner diameter of $90 \mathrm{~mm}$, supplied with two viewing windows for visual, video and photography observations, on the outer wall of which electric heater was wound for providing the liquid temperature necessary in each experiment. On the top part of the vessel was mounted vertical condenser (2) type of pipe in a pipe and the tap water was used as coolant. Over the condenser was installed the chamber (3) for heating of the sample.

The sphere (4) rigidly fixed on a special tubular probe, by which was lifted to a heating zone, and then submerged into a liquid at synchronous inclusion of system of data gathering from temperature sensors. 
To measure the temperature of the sphere was used a Chromel-Alumel thermocouple with diameter of thermo electrodes of $0.2 \mathrm{~mm}$, embedded with the help heat resistant glue VS-10T in a blind hole with a diameter of $0.8 \mathrm{~mm}$ and depth of $15 \mathrm{~mm}$ drilled at an angle $45^{\circ}$ to a vertical axis. To measure the temperature of the liquid in the bulk tank and a heating device also was used a Chromel-Alumel thermocouple.

Also the high-speed video shooting by means of highspeed video camera VS-FAST of firm VIDEOSCAN was done. During experiment after indication of the thermocouple in the center of sphere achieved the demanded value the synchronizing signal including record of video shots in a computer memory was given to the video camera.

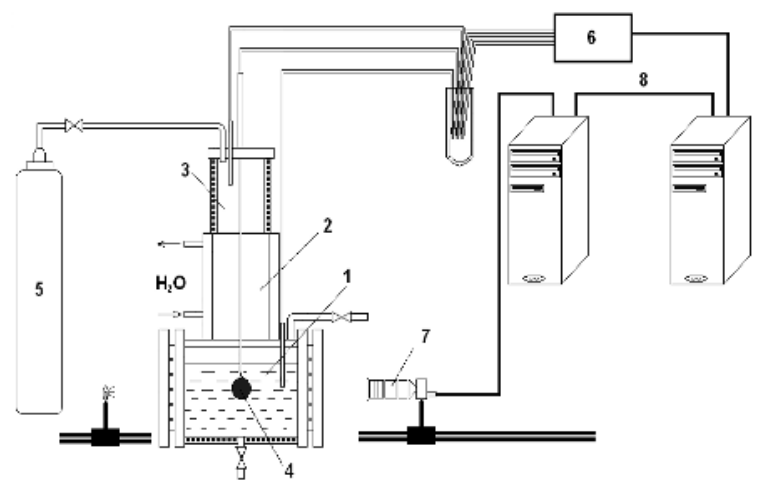

Fig. 1. Experimental facility. 1 - tank with an investigated liquid, 2 - the condenser, 3 - the chamber for heating of the sample, 4 - sphere, 5 - argon cylinder , 6 - ADC, 7 - a highspeed video camera, 8 - a synchronization line.

More detailed experimental facility and the method of research is described in [7].

\section{Results}

Figure 2 shows photos of saturated Freon-113 film boiling. The left image was acquired with the video in the reflected light. The right photo was taken in transmitted light. We can see the presence the waves at the liquidvapor interface. The amplitude of these waves is comparable or even higher than the average thickness of the vapor film. Their form is similar to wave form on the surface of thin films of liquid observed in [8].

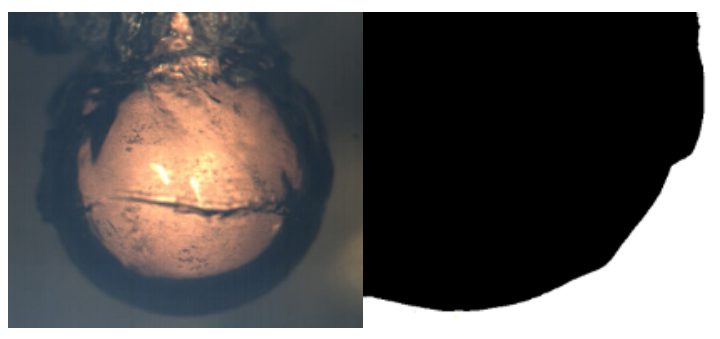

Fig. 2. Photos of film boiling. Saturated Freon-113, $d=15 \mathrm{~mm}$, $\Delta \mathrm{T}=90 \mathrm{~K}$ (left), frequency of shooting - $505 \mathrm{~Hz}$, the exposure $500 \mu \mathrm{s}$. Saturated Freon-113, $\mathrm{d}=25 \mathrm{~mm}, \Delta \mathrm{T}=130 \mathrm{~K}$., frequency of shooting $-505 \mathrm{~Hz}$, the exposure $-24 \mu \mathrm{s}$.
It should be noted that the geometry of the waves can be two-dimensional and three-dimensional (figure 3), depending on the diameter of the sphere, liquid properties and the temperature difference, as discussed in [9].

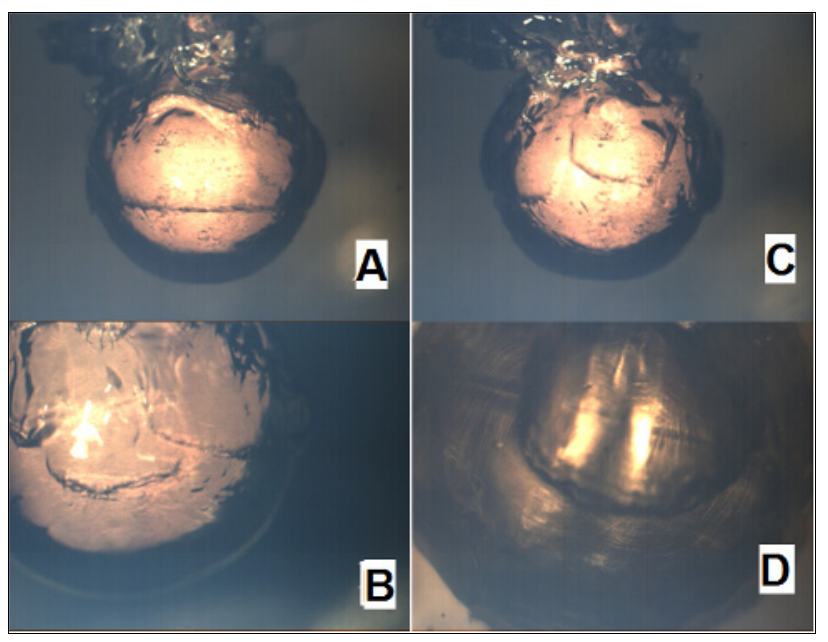

Fig. 3. Photos of film boiling. A $-\mathrm{d}=15 \mathrm{~mm}$, delta $\mathrm{T}=125 \mathrm{~K}$, saturated Freon-113, B - d $=25 \mathrm{~mm}$, delta $\mathrm{T}=125 \mathrm{~K}$, saturated Freon-113; $\mathrm{C}-\mathrm{d}=15 \mathrm{~mm}$, delta $\mathrm{T}=152 \mathrm{~K}$, saturated Freon113; $\mathrm{D}-\mathrm{d}=25 \mathrm{~mm}$, delta $\mathrm{T}=300 \mathrm{~K}$, saturated water.

In figure 4 shows the average thickness of the vapor film at boiling of saturated Freon-113, depending on the angle for a sphere with a diameter of $15 \mathrm{~mm}$ at different temperature differences. It may be noted that for small temperature differences the average thickness of the vapor film always increases with increasing angle. On the other hand, for large temperature differences $(150 \mathrm{~K})$ there is a very weak dependence of the average thickness of the angle from 0 to 40 degrees. At large angles observed the same dependence as for small temperature differences.

Can also be seen that at higher temperature difference average vapor film thickness on the bottom of the sphere $\left(0^{\circ}\right)$ is 1.5 times more than at low temperature differences. I.e. in this case the amplitude of the initial quasi-periodic oscillations on the bottom of the sphere more than at low temperature differences. Therefore waves with initially higher amplitude increases less than the small wave in moving to the top of the sphere.

In general, the amplitude of the oscillations on the bottom of the sphere depends not only of the temperature difference but also affects by the diameter of the sphere. Generally, the larger diameter of the sphere the bigger initial amplitude is. I.e. in the case of increasing the diameter we should expect less dependence of angle on the average thickness of the vapor film.

This is one of the reasons for unchanging average vapor film thickness on the equator $\left(90^{\circ}\right)$ at increasing diameter of the sphere from $25 \mathrm{~mm}$ to $30 \mathrm{~mm}$ at boiling saturated Freon-113, as described in [10]. 


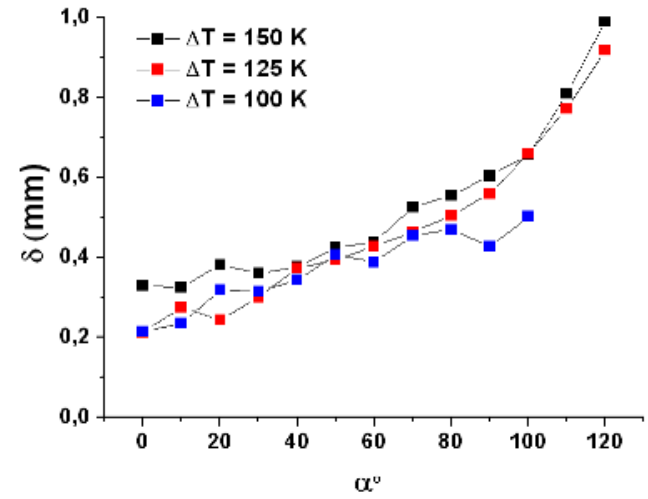

Fig. 4. The average thickness of the vapor film depending on the angle. Saturated Freon-113, d = $15 \mathrm{~mm}$, frequency of shooting - $505 \mathrm{~Hz}$, the exposure - $24 \mu \mathrm{s}$.

In the case of boiling saturated distilled water (figure 5) on a sphere with a diameter of $20 \mathrm{~mm}$ at $\Delta \mathrm{T}=300 \mathrm{~K}$, the average thickness of the vapor film is independent of the angle between 0 and 60 degrees.

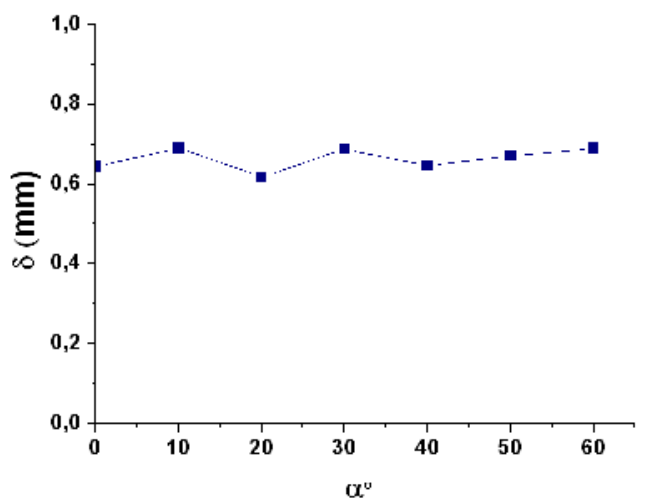

Fig. 5. The average thickness of the vapor film depending on the angle Saturated water, $\mathrm{d}=20 \mathrm{~mm}, \Delta \mathrm{T}=300 \mathrm{~K}$, frequency of shooting $-505 \mathrm{~Hz}$, the exposure $-24 \mu \mathrm{s}$.

This situation occurs apparently because of that in the case of boiling water initial average thickness of the vapor film and initial amplitude of the waves are much greater than at the boiling of Freon-113.

On figure $6 \mathrm{a}$ is presented the cumulative distribution function of vapor film thickness as a function of angle for the boiling of Freon-113 on sphere $20 \mathrm{~mm}$ diameter with temperature difference equal to $125 \mathrm{~K}$. It can be seen that at small angles the cumulative distribution function is small dependent from the angle. And at high angles shifted to the right in all range of vapor film thickness. However, there is a strong shift to the right at large thicknesses. And, therefore, the reduction of heat transfer with an increase of the angle should be less significant than the increase in the average thickness of the vapor film, because heat flux is inversely proportional to the thickness of the vapor film.

With increasing temperature difference of up to $150 \mathrm{~K}$ (Figure 6b), as in the case of the average thickness of the vapor film at small angles of the cumulative distribution function is almost independent of the angle.

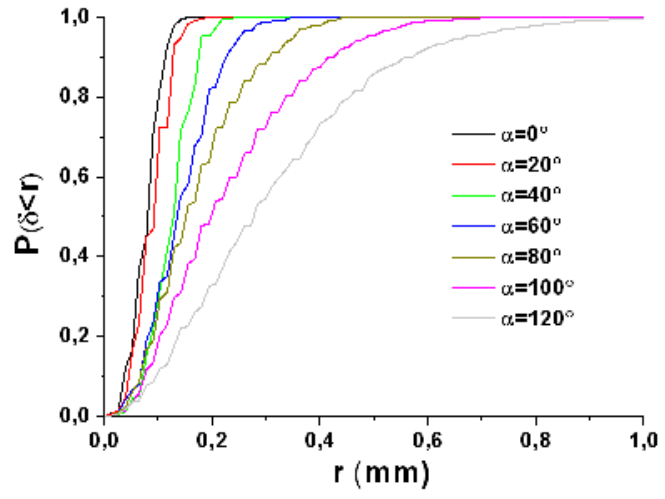

a)

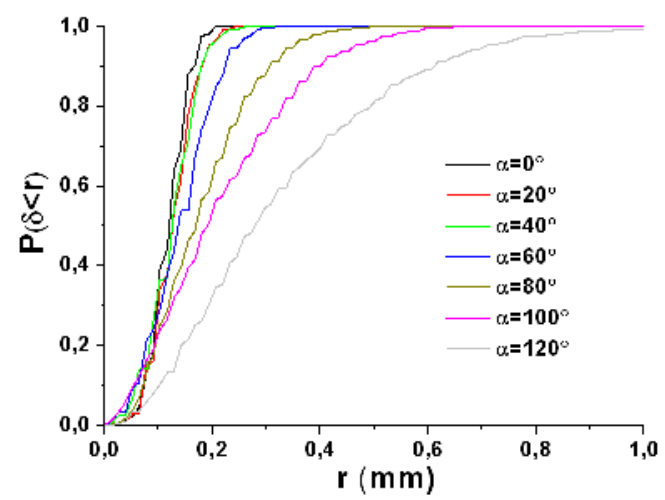

b)

Fig. 6. The cumulative distribution function depending on the angle. a) Saturated Freon-113, $d=15 \mathrm{~mm}, \Delta \mathrm{T}=125 \mathrm{~K}$ b) saturated Freon-113, $\mathrm{d}=15 \mathrm{~mm}, \Delta \mathrm{T}=150 \mathrm{~K}$. Frequency of shooting - $505 \mathrm{~Hz}$, the exposure - $24 \mu \mathrm{s}$.

Figure 7 shows that at film boiling o saturated water in the small-angle graphs undergo small changes with increasing angle. And at large angles visible shift to the right for large vapor film thickness.

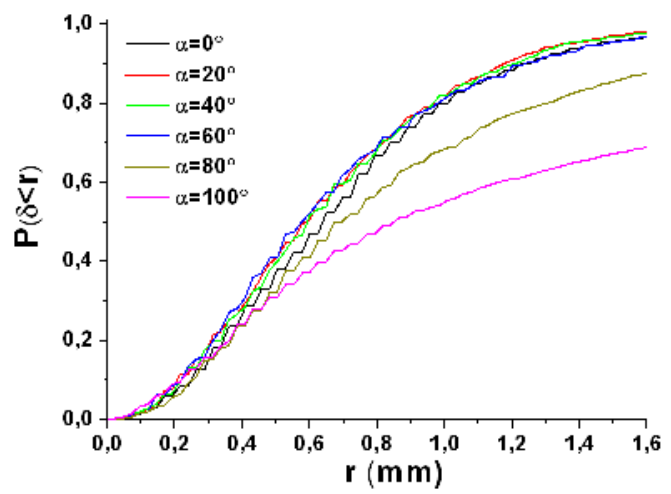

Fig. 7. The cumulative distribution function depending on the angle Saturated water, $\mathrm{d}=20 \mathrm{~mm}$, at $\Delta \mathrm{T}=300 \mathrm{~K}$, frequency of shooting - $505 \mathrm{~Hz}$, the exposure - $24 \mu \mathrm{s}$.

In terms of heat transfer, the maximum local time heat transfer occurs when the local thickness of the vapor film is small. I.e. average heat flux in the largest contribution is made by the cumulative distribution function with low vapor film thickness. In the present case, view the cumulative distribution function weakly dependent on the 
angle, and therefore the average heat flux should depend small from the angle.

The resulting differences in the change of the average thickness of the vapor film and the cumulative distribution function have an impact not only on the local heat transfer, but also on the temperature field inside the spherical heater. This is more to be manifested at a lower thermal conductivity of the material sphere. Based on theoretical models [11-14] it can be concluded that the lowest temperature should be in the lower point of the sphere. However, based on the data presented in the case of boiling water and boiling Freon-113 at high temperature differences rather large lower part of the sphere should have approximately the same temperature because heat flux to the fluid there are roughly equal. Especially it should be seen in boiling water.

Qualitative shape of the temperature distribution in the sphere, which indirectly obtained, explains the differences in the way the crisis of film boiling. If in the case of small diameter sphere at boiling Freon-113 at first occurs local liquid-solid contact in the bottom of the heater, where in this case must be the lowest temperature, and further gradual increase in the frequency of contacts and their area. In the case of boiling water immediately occurs liquid-solid contact on the large heat-transfer surface area, and the crisis looks more intense. What can explain the approximate equality of the wall temperature in a sufficiently large range of angles.

On the other hand, we can assume that the above possibility of liquid-solid contact at once on a large area with liquid subcooling leads to an explosive boiling crisis. Which has never been observed at boiling of subcooled Freon-113, but in turn was observed at boiling distilled water with a significant subcooling.

The emergence of three-dimensional structure of the waves when increasing diameter sphere should also lead to a more uniform temperature distribution on the surface of the sphere. And in the case of boiling water threedimensional structure of waves takes place even at a sufficiently small diameter. This fact is an additional reason for a more intense crisis of film boiling distilled water.

\section{References}

1. S. Aziz, G.F. Hewitt, D.B.R. Kenning, Proc. 8th Int. Heat Transfer Conf. V. 5, 2149-2154 (1986)

2. G. Son, V.K. Dhir, Numer. Heat Transfer, Part B 52, 153-177 (2007)

3. G. Son, V.K. Dhir, Int. J. of Heat and Mass Transfer 51 1156-1167 (2008)

4. Yu.A. Kuzma-Kichta, Cand. Sci. (Tech.) Dissertation, Moscow: Moscow Power Engineering (1973) (in Russian)

5. S. Toda, M. Mori, Proceedings of the 7th International Heat Transfer Conference, Munich, West Germany, v. 4, 173 (1982)

6. S. Nishio, H. Ohtake, JSME Int. J., Ser. II (1992)

7. A. M. Agaltsov, A. B. Pohodalova, Yu. B. Shmelkov, High Temperature, V. 49, No. 6, 890-896 (2011)
8. V.E. Nakoryakov, B.G. Pokusaev, I.R. Shrayber, Moscow: Energoatomizdat, 248 (1990) (in Russian)

9. A. M. Agaltsov, I.A. Fedoseenko, EPJ Web of Conferences, 25, (2012)

10. A. M. Agaltsov, Yu. A. Zeigarnik, Actual issues of Thermophysics and physical hydrodynamics (2012)

11. T.H.K. Frederking, J.A. Clark, Adv. Cryog. Eng., v. 8, $501(1963)$

12. R.C. Hendricks, K.J. Baumeister, NASA Tech.Note, TND_5124 (1969)

13. E.V. Ametistov, V.V. Klimenko, Yu.M. Pavlov, Moscow: Energoatomizdat (1995) (in Russian)

14. V.K. Dhir, G.P. Purohit, Nucl. Eng. Des., v. 47, 49 (1978) 